sive cervical-smear specialists should realize that carcinoma may be present in other parts of the urogenital system and, of course, elsewhere. The only symptom that this patient had had was two rather excessive periods.I am, etc,

West Harrow,
Middlesex.

\section{Oral Contraceptives and Breast Cancer}

SIR,-Mr. J. J. Shipman has aired an important question by his letter on this subject (5 September, p. 629). He reports two patients who presented with evidence of breas cancer and who were, at the time, taking oral contraceptives. In view of the very widespread use of oral contraceptives among young women, and the fact that breast cancer is the commonest malignancy in females, it would indeed be surprising if none of these young women developed breast cancer. The similar question of whether oestrogens (which are used very widely also) are liable to induce breast cancer is one which has been discussed for the last 25 years, ${ }^{1}$ but is still undecided. An answer to both questions could only be provided by a careful sampling of the population.

Mr. Shipman, however, suggests that an existing hormone-sensitive breast cancer may be influenced adversely by these progestogenoestrogen tablets. It is, of course, equally possible that the tumour may be influenced favourably by these hormones, and in fact the experimental evidence appears to favour the latter possibility. Professor Huggins, of Chicago, demonstrated in 1959 that dimethylbenzanthracene-induced mammary adenocarcinoma in rats was hormone-sensitive. It responds to oophorectomy, adrenalectomy, hypophysectomy, and androgen administration, as does the hormone-sensitive human breast cancer. Huggins ${ }^{2}$ further demonstrated that combined high-dose progesterone and low-dose oestrogen administration was capable of extinguishing the tumour in over $50 \%$ of the rats. This observation may possibly have an application in the treatment of human breast cancer, although a suitable progestogen and dosage level still remain to be worked out. Nevertheless, the experimental evidence to date is in favour of depression, and not stimulation, of tumour growth by the hormone combination.

Finally, Mr. Shipman suggests that as oral contraceptives may cause an increased blood flow to the breast, their use should be discontinued in patients with suspected or proved breast cancer. While I agree with such a decision until further experience is accumulated, I do not agree with the reasoning. Westberg ${ }^{3}$ reported 224 cases of breast cancer in pregnant and lactating women. He concluded that pregnancy does not appear to exert any great effect upon the prognosis of breast cancer, except for the tendency to delay in diagnosis and treatment. Surely one would expect the grossly increased blood flow to the breasts in pregnancy to be even more dangerous than the premenstrual congestion seen with the use of the "pill"?-I am, etc.,

Peter MacCallum Clinic,
Melbourne, Australia.

REFERENCES

1 Allaben, G. R. and Owen, S. E., f. Amer. med. Ass., 1939, $112,1933$.

${ }^{2}$ Huggins, C., Moon, R. C., and Morii, S., Proc. Nat. Acad. Sci., 1962, 48, 379.

Westberg, S. V., Acta obstet. gyn. Scand., 1946,

\section{Haemodialysis Disequilibrium}

SIR,-Dr. S. M. Rosen and others (12 September, p. 672) reported further investigations into the haemodialysis-disequilibrium syndrome. We note that they were able to confirm our findings that this appears to be due to delay in clearance of urea from the cerebrospinal fluid, with consequent creation of an osmotic gradient between plasma and cerebrospinal fluid. ${ }^{1}$ The authors conclude that this upset can best be prevented by frequent haemodialysis at low levels of biochemical disturbance. This is not the only answer to the problem, however, and we should like to point out that we have published further work on the pathogenesis of this syndrome and have demonstrated that clinical and electroencephalographic evidence of disequilibrium can be prevented by a fourfold increase in the glucose concentration in the rinsing fluid. ${ }^{2}$ This modification in dialysis technique is an extremely simple one and permits efficient dialysis, which is of particular value when dealing with patients with a high level of catabolism.-We are, etc.,

\section{Artificial Kidney Unit, Royal Infirmary, \\ A. C. KenNedy. \\ A. L. Linton. \\ R. G. LUKE.}

REFERENCES

Kennedy, A. C., Linton, A. L., and Eaton, J. C., Lancet, 1962, 1. 410. A and Renfrew, S., ibid., 1963, 1, 408 . - and Dinwoodie, A., ibid. $1964,1, \overline{790}$.

\section{Percutaneous Transhepatic Cholangiography}

SiR,-I am glad to see that Drs. S. G. Elkington and D. C. Bernstein have recorded a small series of cases investigated by percutaneous transhepatic cholangiography (19 September, p. 733), but the technique they describe carries a greater risk of complication than that which I have described in two papers $^{12}$ and at the Association of Surgeons of Great Britain and Ireland meeting in 1957. The risk of haemorrhage and biliary peritonitis is much reduced by inserting a needle $25 \mathrm{~cm}$. in length and $1 \mathrm{~mm}$. bore just below the ninth costal cartilage at a point at the junction of the outer and middle third of a line drawn from the midline to the lateral margin of the abdominal wall. The needle is inserted at an angle of 45 degrees to the horizontal and 15 degrees internal to the vertical plane. Aspirations should be made with a $5 \mathrm{ml}$. syringe at frequent intervals during the introduction and withdrawal of the needle. The point selected is external to the gallbladder but reaches the right hepatic duct system at a depth of some 15 centimetres from the surface of the liver. The long track prevents oozing of bile or blood from the puncture wound on the surface of the liver and avoids risk of direct penetration of the common hepatic duct or vessels. In over 60 cases in which this technique has been used the mortality rate has been nil and no case of biliary peritonitis or intra-abdominal haemorrhage has occurred. If the gallbladder is entered (as shown by the injection of contrast media) then the abdomen should be opened, and this has had to be done on three occasions.

There was a discussion on this subject at the Royal Society of Medicine in 1962, and it is to be hoped that this valuable method of investigation of cases of jaundice will be more widely used. The technique is, however, most important if accidents are to be avoided.-I am, etc.,

London, W.1.

H. A. KIDD.

REFERENCES

1 Kidd, H. A., Arch. Surg., 1956, 72, 262. Transactions International Congress of Surgery, Copenhagen, 1955.

\section{Leukaemia and Phenylbutazone}

SIR,-I read with interest the communications relating to the association of leukaemia and phenylbutazone appearing in recent issues of your journal, ${ }^{1-3}$ and I followed the relevant communications which appeared in earlier issues of your journal. ${ }^{4}$ I have also come across one instance of acute myeloid leukaemia in a 46-year-old male who had taken phenylbutazone intermittently for a significant period before the onset of leukaemia. It appears that, in general, myelotoxic agents have a leukaemogenic propensity. ${ }^{\circ}$ In this context, and against the background of informations listed above, the suggested association between phenylbutazone and leukaemia must be more critically evaluated. I write this letter to draw the attention of all concerned to one particular aspect of this problem. Examination of relevant clinical data would show that most of the subjects so far reported and discussed with reference to the leukaemogenic propensity of phenylbutazone were elderly or old persons who had been suffering from some sort of painful condition affecting the bones. Is it possible that inflammatory, degenerative, and collagenous affections of osseous tissue tend to make the enclosed haemopoietic tissue more vulnerable to the damaging effect of a myelodepressive agent like phenylbutazone? The higher incidence of leukaemia that has been reported in patients with spondylitis deformans receiving deep $x$-ray therapy may in this perspective be considered as illustrative of the greater vulnerability of such patients to the damaging effects of $x$-rays. - I am, etc.,

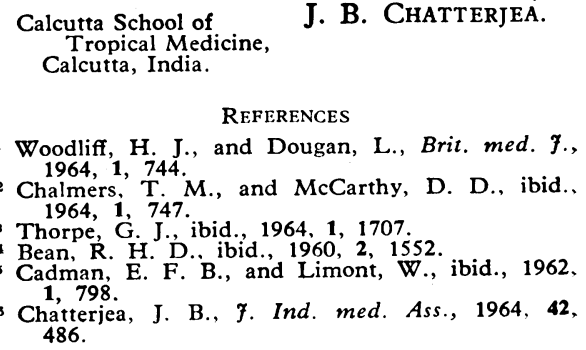

\section{Prolonged Arteriospasm after Ergotamine}

SIR,-Dr. E. Byrne-Quinn's report of a case of overdose with ergotamine tartrate (29 August, p. 552) gives further warning of the great caution which must be exercised in the use of this drug, and the importance of such warnings cannot be over-emphasized.

It is not true, however, that there are " no reported cases of arteriospastic disease from the oral administration of ergotamine tartrate or its related alkaloids in migraine" (our italics). Fuchs and Blumenthal ${ }^{1}$ recorded two cases of ergotism in 1950 . Both had severe symptoms but in neither was amputa- 
tion necessary. The one case had taken only small oral doses of ergotamine; the other was receiving subcutaneous dihydroergotamine. This report was referred to in our article ${ }^{2}$ in the British Medical fournal four years ago. Our own report was on gangrenous ergotism in a woman of 45 who had taken only 7 tablets, each containing $1 \mathrm{mg}$. ergotamine tartrate, over three days-not for migraine. Amputation of both legs, the right thumb, and tip of right index finger had to be performed.

We believe that migraine confers immunity to possible side-effects from ergotamine, and further that the route of administration is probably of little importance. In some cases side-effects may arise because of abnormal response to accepted therapeutic dosage. The smallest possible dose that will control the symptoms of migraine must be found by gradually increasing the dose with each attack-increasing from $1 \mathrm{mg}$. by $1 \mathrm{mg}$. increments, respectively, in subsequent attacks until either a satisfactory dose is thus safely found, or side-effects are too severe. Paraesthesiae, coldness, and pains in the extremities should be reported at once.-We are, etc.,

E. A. CAMERON.
Ashington General Hospital,
Northưmberland.

Western General Hospital,

E. B. FRENCH

Edinburgh.

REFERENCES

Fuchs, M., and Blumenthal, L. S., 7. Amer, med. Ass, $1950,143,1462$

Cameron, E. A., and French, E. B., Brit. med. 7. $1960,2,28$.

\section{Typical Medical Students}

SIR,-Studies defining various types of student will be of increasing importance if we are to work out educational programmes that will best fit the teaching to the taught. Dr. H. J. Walton and his colleagues (19 September, p. 744) have done an important piece of work in attempting to sketch the typical medical student. But in presenting just four types I think they have over-simplified the picture. Their technique of delegate-analysis produces bipolar factors. Unless they have treated the data in some way not described in the text, then I would think for each type outlined another composite student with " mirror, or opposite, characteristics" exists ; eight in all.

The authors describe No. 4, the "patientcentred graduate," as the potential psychiatrist. Equally there is 4 (b). He is the man who does not care much for contact with patients though, perhaps because he does not look too deeply, is not disturbed by them ; he is judged a good student by his teachers, often in the top quartile of medicine and of surgery ; his standing in the community is important to his satisfaction as a doctor; he has little interest in research ; he favours technical procedures more than problems of personality ; whilst at university he has had enough time for sport, physical exercise, etc. ; he has not considered following a career in psychiatry. Who is 4 (b), then ? A good provincial radiologist perhaps ? $-\mathrm{I}$ am, etc.,

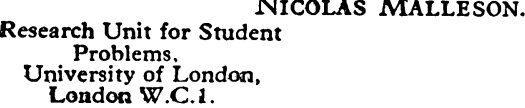

\section{Neurological Symptoms with Phenothiazines}

SIR,-It has recently been reported in the daily press that phenothiazines-in particular chlorpromazine (Largactil)-are dangerous drugs which may induce irreversible neurological changes. This followed a paper read by Hunter et al..$^{1}$ at the Royal Society of Medicine. The authors suggested that permanent brain damage may result from these drugs when given over a prolonged period. They described thirteen patients who exhibited choreiform movements, a Parkinsonian syndrome, and dystonic spasms affecting head, neck, face, mouth, and tongue. They suggested that much greater caution is indicated in the prolonged use of the phenothiazines, because in these cases the neurological side-effects were irreversible and apparently permanent.

This widely reported picture has worried some of my patients who have been taking chlorpromazine. All psychiatrists would agree that the discovery of the phenothiazines has been one of the major advances in psychological medicine, and it would be a pity if this report deterred doctors and patients from using these drugs.

The cases reported by Hunter and his colleagues were all brain-damaged, and every one'suffered from dementia. Six of the 13 had been leucotomized, nine had had E.C.T. from 14 to 212 times, and two had had insulin-coma treatment. They had all been on phenothiazines for $1 \frac{1}{2}$ to 5 years before abnormal movements were first recorded.

The fact that all of these patients were brain-damaged and demented prior to the administration of the drug surely invalidates the suggestion that phenothiazines may produce irreversible neurological change. Hunter et al. surveyed 450 patients in this review and presumably thev saw many who were not brain-damaged being treated with phenothiazines. It is significant that only the brain-damaged reacted permanently to the drug. I would suggest that where there is no organic damage to the brain phenothiazineinduced extrapyramidal movements are entirely reversible on stopping the drug.

I have observed that the earliest sign of phenothiazine-induced abnormal movements is a hesitancy in speech sometimes leading to difficulty in enunciating words. If this symptom appears the dose should be reduced or the drug changed.-I am, etc.,

London $\mathbb{W} 1$

\section{S. BOCKNER}

1 Hunter, R., Earl, C. J., and Thornicroft, S., Proc. roy. Soc. Med., 1964, 57, 758 .

\section{Ampicillin for Typhoid Carriers}

SIR,-Dr. K. F. Anderson in his letter on the use of amnicillin for typhoid carriers (29 August, p. 571) states that, " to obtain negative faecal cultures for at least a year tells us nothing about the condition of the gallbladder or whether viable bacilli are still present in one or more calculi." This is very obviously true, but the findings do tell us that, irrespective of the condition of the gall-bladder, the carrier has ceased to excrete the organism for one year. This is really all that matters.
The pathological conditions that underlie the carrier condition are well known to all who deal with typhoid carriers. The investigations which should ideally be carried out are also familiar, but carrying them out is not always so easy. Has Dr. A.nderson ever tried to pass a duodenal tube on a mentally deranged patient? In any case, does it matter? If a patient who has been excreting Salmonella typhi in every specimen of faeces for, say, 20 years stops excreting it for a year, after any form of treatment, is it essential to intubate that patient, or can it not be assumed that the organism has disappeared from the faeces because it has ceased coming down the bile duct? Does it really matter if typhoid bacilli are locked up inside some calculus, or if Vi titres remain high, ${ }^{1}$ so long as $S$. typhi is no longer being excreted from the body?

Dr. Anderson claims that "ampicillin ... can never replace surgery for the removal of irreversibly diseased foci which cannot be sterilized by antibiotic therapy." How does he know ? Ten or twelve years ago resection of lung was the approved treatment for some forms of pulmonary tuberculosis: this has now been replaced by antibiotic therapy, and in the process of healing some tubercle bacilli are probably locked up in lung-scar tissue. Would Dr. Anderson still insist on surgery ? Yet the analogy with the typhoidcarrier state may be a close one.

The problem of the typhoid carrier is possibly greater than Dr. Anderson realizes. I have recently heard from one European doctor who has over 400 carriers in his area, and in another European city at least 900 are known-a great deal of surgery, and a lot of gall-stones to grind. If ampicillin can help to deal with such problems, then it will be a most valuable addition to our therapy. Only painstaking follow-up of treated carriers can answer the question.-I am, etc.,

$$
\begin{array}{ll}
\begin{array}{l}
\text { Fazakerley Hospital, } \\
\text { Liverpool 9. }
\end{array} & \text { A. B. Christie. } \\
\text { ReferencB } & \text { Christie, A. B., Brit. med. 7., 1964, 1, } 1609 .
\end{array}
$$

\section{Ruptured Uterus after Buccal Oxytocin}

SIR,-Following the report by Dr. P. M. Leney (12 September, p. 689) of a case of ruptured uterus after buccal oxytocin, may I record two cases with violent contractions which gave rise to considerable anxiety and near death in one case? Both cases were given buccal Pitocin citrate (oxytocin) 24 hours after failed surgical induction.

The first case, para $2+0$, was given an Edinburgh course, ${ }^{1} 100$ units oxytocin citrate to burgh then 200 units to alternate parabuccal start, then 200 units to alternate parabuccal spaces at 30-me contractions lasting 50 seconds strong uterine contractions minutes. The remainwere occurring evere removed from the mouth, ing linguets were removed out. At vaginal which was thoroughly rinsed out. At vaginal examination the cervix was found to be dilated to $4 \mathrm{~cm}$. Pethidine, $100 \mathrm{mg}$., intravenously. The contractions completed 20 abated, the second stage being completed 20 minutes later. The baby was in good condition at regular. The husband was impressed by the rapidity of the labour but the obstetrician was acutely distressed.

The second case, para $2+0$, was started on Worcester course ${ }^{2}$-at half-hourly intervals $100,100,200,200,400,400$ units. After 